\title{
Surface roughness dependent osteoblast and fibroblast response on poly(L-lactide) films and electrospun membranes
}

\author{
Clarisse Ribeiro, ${ }^{1,2 *}$ Vitor Sencadas, ${ }^{1,3 *}$ Anabela C. Areias, ${ }^{1}$ F. Miguel Gama, ${ }^{4}$ \\ Senentxu Lanceros-Méndez ${ }^{1,2}$ \\ ${ }^{1}$ Centro/Departamento de Física da Universidade do Minho, Universidade do Minho, Campus de Gualtar, $4710-057$ Braga, \\ Portugal \\ ${ }^{2}$ INL-International Iberian Nanotechnology Laboratory, 4715-330 Braga, Portugal \\ ${ }^{3}$ Instituto Politécnico do Cávado e do Ave, Campus do IPCA, 4750-810 Barcelos, Portugal \\ ${ }^{4}$ IBB-Institute for Biotechnology and Bioengineering, Centre of Biological Engineering, Universidade do Minho, Campus de \\ Gualtar, 4710-057 Braga, Portugal
}

Received 14 September 2014; revised 21 October 2014; accepted 29 October 2014

Published online 11 November 2014 in Wiley Online Library (wileyonlinelibrary.com). DOI: 10.1002/jbm.a.35367

\begin{abstract}
Poly(L-lactide) electrospun mats with random and aligned fiber orientation and films have been produced with degrees of crystallinity ranging from 0 up to nearly $50 \%$. The overall surface roughness is practically constant irrespective of the sampling areas $(1 \times 1 \mu \mathrm{m}$ to $20 \times 20$ $\mu \mathrm{m})$ for degrees of crystallinity below $30 \%$, increasing for higher degrees of crystallinity for the larger sampling areas. Further, due to fiber confinement, surface roughness variations are smaller in electrospun mats. Samples with $50 \%$ of crystallinity show the lowest osteoblast and the
\end{abstract}

highest fibroblast proliferation. Therefore, it is verified that higher roughness promotes lower osteoblast but higher fibroblast proliferation. The overall results indicate the relevant role of the sub-microenvironment variations associated to the microscale roughness in determining the different cell responses. $\odot 2014$ Wiley Periodicals, Inc. J Biomed Mater Res Part A: 103A: 2260-2268, 2015.

Key Words: poly(I-lactic acid), tissue and biomedical engineering, cell-material interface

How to cite this article: Ribeiro C, Sencadas V, Areias AC, Gama FM, Lanceros-Méndez S. 2015. Surface roughness dependent osteoblast and fibroblast response on poly(L-lactide) films and electrospun membranes. J Biomed Mater Res Part A 2015:103A:2260-2268.

\section{INTRODUCTION}

Cell/material interactions are a key issue for cell biology studies and biomedical applications. It has been reported that cell response is sensitive to material topography and functional characteristics, leading to specific cellular responses. ${ }^{1-4}$ Thus, mechanisms associated to cell adhesion, migration, spreading, and differentiation can be controlled by tailoring physical properties, surface chemistry, mechanical properties, micro, and nanostructure. ${ }^{5,6}$ Cells attachment to membranes or scaffolds via local adhesion points, connecting the cytoskeleton to the polymer surface, is affected by surface chemistry ${ }^{7}$ (e.g., presence of ligands), electrostatic charge, ${ }^{8}$ wettability (surface polarity), ${ }^{9}$ mechanical properties, ${ }^{10}$ and surface topography. ${ }^{7}$ In this sense, understanding cell-biomaterial interaction is critical in order to design novel successful biomaterials with increased and tai- lored functionality for applications such as wound healing, immune response, and tissue integration.

Surface roughness may be considered on different scales (e.g., nano or micrometric), each level of surface patterning potentially impacting the cell-material interactions. Washburn et al. ${ }^{11}$ reported on osteoblast response to polymer degree of crystallinity. Samples with a gradient of crystallinity were prepared and it was shown that cells are sensitive to topographic features of the order of $5 \mathrm{~nm}$. Further, the observed inhibition of proliferation of cells was not influenced by changes in adherent proteins but directly ascribed to changes in substrate roughness. Tissue in-growth through porous scaffolds composed of semicrystalline or amorphous PLA implanted in rat mesentery ${ }^{12}$ lead also to the conclusion that cell proliferation is adversely affected by substrate roughness, reporting a reduction of tissue in-growth

Additional Supporting Information may be found in the online version of this article.

* These authors contributed equally to this work.

Correspondence to: S. Lanceros-Mendez; e-mail: lanceros@fisica.uminho.pt

Contract grant sponsor: the Portuguese Foundation for Science and Technology (FCT); contract grant numbers: C/FIS/UI607/2011, PTDC/ CTM-NAN/112574/2009

Contract grant sponsor: FCT; contract grant numbers: SFRH/BPD/63148/2009, SFRH/BPD/90870/2012

Contract grant sponsor: Matepro-Optimizing Materials and Processes, Programa Operacional Regional do Norte, Quadro de Referência Estratégico Nacional" (QREN), "Fundo Europeu de Desenvolvimento Regional" (FEDER); contract grant number: NORTE-07-0124-FEDER-000037 
through crystalline scaffolds after 10 days, which is different from the results obtained with the amorphous scaffolds.

A qualitative and quantitative study of human osteoblast adhesion on materials with various surface roughness was performed using a metallic Ti6Al4V alloy. ${ }^{2}$ It was found that cells oriented in a parallel manner in polished surfaces, never attaining confluence in sand-blasted surfaces and bearing a stellate shape, with impaired extracellular matrix (ECM) organization. The study of the effect of titanium controlled surface features ${ }^{13}$ lead to the conclusion that the most influential surface dimension in promoting osteoblast differentiation was nano-submicron hybrid roughed surfaces as it initiates integrin activation and accelerates cyclins expression. In addition, through real-time monitoring of live-stem cell dynamics, it was found that surface height of 2-4 nm induces significant reorganization of cytoskeletons, which determines subsequent osteoblast differentiation.

Poly (L-lactic acid) (PLLA) is one of the most widely used biomaterials, due its low density, easy manufacturing, and biodegradability, leading to a materials with high potential in tissue and bioengineering applications when used both in the form of films or micro and nanofibers. ${ }^{14,15}$ There are several methods to induce surface nanopatterning such as softlithography, dip-pen, template, self-assembling, selective etching, and selective chemical methods. ${ }^{7}$ Thermal annealing is another approach to tailor surface roughness on materials such as PLLA, leading to different degrees of crystallinity depending on the annealing temperature and time., ${ }^{9,15}$

There are some studies pointing out the relevance of degree of crystallinity and surface roughness on cellular response, but there is still no clear knowledge or trends on those issues, which in turn may be different for different cell types. In the present work, the influence of PLLA surface roughness at different measuring scales and degree of crystallinity in cell attachment and proliferation of preosteoblast and fibroblast cells is reported.

\section{EXPERIMENTAL SECTION}

\section{Materials}

PLLA, with an average molecular weight of 217,000225,000 $\mathrm{g} \mathrm{mol}^{-1}$, Purasorb PL18 was supplied by Purac (Netherlands). $N, N$-dimethylformamide (DMF, Merck) and dichloromethane (DCM, Sigma-Aldrich), both analytical grade, were used as received.

PLLA was dissolved in $3 / 7(\mathrm{v} / \mathrm{v})$ mixture of DMF/DCM, to achieve a polymer concentration of $10 \mathrm{wt} \%$ in the solution. The dissolution process was conducted at room temperature until complete dissolution using a magnetic stirrer.

Flexible films with a thickness of $\sim 40 \mu \mathrm{m}$ were obtained by spreading the solution on a glass substrate, which was then maintained in an oven at $80^{\circ} \mathrm{C}$ over $1 \mathrm{~h}$ (HERAEUS Vacuotherm) to ensure total solvent evaporation. To obtain amorphous polymer films and remove material processing and thermal history, the samples were heated up to $200^{\circ} \mathrm{C}$ and remained at that temperature for $10 \mathrm{~min}$ before being removed and cooled to room temperature.

PLLA electrospun samples were obtained by electrospinning according to the procedure explained elsewhere. ${ }^{15,16}$
TABLE I. Degree of Crystallinity of the PLLA Films and Electrospun Fiber Membranes After Different Thermal Annealing Processes

\begin{tabular}{lcc}
\hline Temperature $\left({ }^{\circ} \mathrm{C}\right)$ & Time $(\mathrm{min})$ & $\begin{array}{c}\text { Degree of } \\
\text { Crystallinity }(\%)\end{array}$ \\
\hline As spun fibers or film & 0 & 0 \\
70 & 60 & 20 \\
90 & 10 & 30 \\
140 & 1440 & 50 \\
\hline
\end{tabular}

The data shown correspond to electrospun membranes with $583 \pm 225 \mathrm{~nm}$ fiber diameter and films with $\sim 40^{\circ} \mu \mathrm{m}$ thickness, ${ }^{16,17}$ similar results were obtained for other samples. All results present standard deviation of $\pm 6 \%$.

Electrospun fiber mats and films were submitted to thermal annealing at different temperatures according to Table I to achieve samples with different degrees of crystallinity. As shown in Ref. [16, PLLA samples are processed in an amorphous state but contain numerous crystal nuclei that rapidly grow when the samples are subjected to thermal annealing. Annealing temperature and time allowing to tailor the degree of crystallinity of the samples.

\section{Sample characterization}

Scanning electron microscopy (SEM). The samples were coated with a thin gold layer using a sputter coating (Polaron, model SC502) and their morphology (Supporting Information Fig. S1) was analyzed using SEM (Quanta 650 from FEI) with an accelerating voltage of $10 \mathrm{kV}$. The mean PLLA fiber diameter were calculated using SEM images of 40 fibers taken at $1000 \times$ magnification and Image J software.

Differential scanning calorimetry (DSC)-The thermal behavior of the PLLA electrospun mats was analyzed by DSC (Supporting Information Fig. S2) with a Perkin Elmer Diamond setup. All the experiments were performed under nitrogen gas flow and heated between 30 and $200^{\circ} \mathrm{C}$ at a heating rate of $10^{\circ} \mathrm{C} \mathrm{min}^{-1}$. The glass transition temperature $\left(T_{\mathrm{g}}\right)$, cold-crystallization temperature $\left(T_{\mathrm{cc}}\right)$, melting temperature $\left(T_{\mathrm{m}}\right)$, cold-crystallization enthalpy $\left(\Delta I I_{\mathrm{cc}}\right)$, melting enthalpy $\left(\Delta I I_{\mathrm{m}}\right)$, and degree of crystallinity $\left(\Delta X_{\mathrm{c}}\right)$ of the samples were evaluated. The degree of crystallinity was calculated after Supporting Information Eq. (S1).

Tapping mode atomic force microscopy (AFM). Doped Si cantilevers were used with spring constants of 20-80 N $\mathrm{m}^{-1}$ driven at a frequency of $320 \mathrm{kHz}$ at a scan rate of 1 $\mathrm{Hz}$ and assays were performed with a Bruker Dimension Icon in air at room temperature. The root-mean-square $(\mathrm{rms})$ roughness was calculated for each image using the instrument software NanoScope Analysis. The standard uncertainty is indicated by the error bars, which represents the standard deviation over at least three measurements performed in different places of each sample.

Contact angle measurements (sessile drop in dynamic mode). The contact angles were performed using the software SCA20 after depositing water droplets $(3 \mu \mathrm{L})$ onto the 
TABLE II. Denomination and Main Characteristics of the Evaluated PLLA Samples

\begin{tabular}{lcl}
\hline Morphology & $\begin{array}{c}\text { Degree of } \\
\text { Crystallinity (\%) }\end{array}$ & \multicolumn{1}{c}{ Denomination } \\
\hline Film & 0 & PLLA Amorphous \\
& 20 & PLLA 20\% \\
Randomly oriented & 50 & PLLA 50\% \\
fibers & 0 & PLLA R Amorphous \\
& 20 & PLLA R 20\% \\
Oriented fibers & 50 & PLLA R 50\% \\
& 0 & PLLA O Amorphous \\
& 20 & PLLA O 20\% \\
& 50 & PLLA O 50\% \\
\hline
\end{tabular}

samples surfaces at room temperature with a Data Physics OCA20 device using ultrapure water as the test liquid. For each PLLA sample, 6 measurements were performed at different locations and the average contact angle was taken for each sample.

\section{Cell culture and proliferation}

Two types of cell lines were used for cell culture: Mouse embryo fibroblast 3T3 and MC3T3-E1 preosteoblast (Riken cell bank, Japan). 3T3 fibroblast were cultivated in Dulbecco's modified Eagle's medium (DMEM, Gibco) containing $4.5 \mathrm{~g} \mathrm{~L}^{-1}$ glucose supplemented with $10 \%$ newborn calf serum (CALF, Invitrogen) and 1\% penicilin/streptomycin (P/S, Biochrom). MC3T3-E1 preosteoblast were cultivated in DMEM containing $1 \mathrm{~g} \mathrm{~L}^{-1}$ glucose supplemented with $10 \%$ Fetal Bovine Serum (FBS, Biochrom) and $1 \% \mathrm{P} / \mathrm{S}$ at $37^{\circ} \mathrm{C}$ in a $95 \%$ humidified air containing $5 \% \mathrm{CO}_{2}$. The medium was changed every 3 days. Circular PLLA samples (the designations and main relevant characteristics of the different PLLA samples are listed in Table II) and glass covers used as control were placed in a 24-well tissue culture polystyrene plate. Cells were seeded at a concentration of $3 \times 10^{4}$ cells $\mathrm{mL}^{-1}$ to each well and incubated in a 95\% humidified air containing $5 \% \mathrm{CO}_{2}$ at $37^{\circ} \mathrm{C}$. Cell culture was carried out up to 6 days.

The proliferation of both cell lines on the different PLLA membranes and glass covers was evaluated by (3-(4,5-Dimethylthiazol-2-yl)-2,5-diphenyltetrazolium bromide) (MTT, Sigma-Aldrich) after 1, 3, and 6 days. MTT is used to measure the number of metabolic active cells based on the quantification of the mitochondrial dehydrogenases activity on viable cells. Four measurements were performed on each sample.

\section{RESULTS}

\section{Samples topography}

The degree of crystallinity of PLLA can be controlled by an annealing process (see also Supporting Information). ${ }^{18}$ Together with the variation of crystallinity, the morphology of the polymer changes from an amorphous flat film to a spherulitic structure, characteristic of semicrystalline polymers. ${ }^{18}$ The evolution of the PLLA film topography with annealing time and temperature was measured by AFM and representative images are shown in Figure 1. Amorphous samples [Fig. 1(a,b)] show just isolated surface contaminants and an rms roughness of $4.8 \pm 0.4 \mathrm{~nm}$ for a $20 \times 20$ $\mu \mathrm{m}^{2}$ area and a rms value of $1.0 \pm 0.1 \mathrm{~nm}$ for an area of 1 $\times 1 \mathrm{~m}^{2}$. It is thus shown that sample roughness depends on sampling area, being the local roughness smaller than the overall roughness of the sample. Samples submitted to thermal annealing show a roughness that increases with annealing time. As increasing annealing time leads to an increase of the degree of crystallinity of the polymer, as shown in Table I, ${ }^{16,17}$ surface roughness is closely related to the degree of crystallinity of the samples. Figure 1(c,d) shows the PLLA sample roughness for a sample with $50 \%$ crystallinity, showing that the roughness for a measured area of $20 \times 20 \mu \mathrm{m}^{2}$ is $45.6 \pm 1.6 \mathrm{~nm}$ [Fig. 1(c)], which is higher when compared to the amorphous PLLA film. It is also observed that thermal annealing leads to a microstructural polymer modification to the characteristic spherulitic structure typical of semicrystalline polymers such as PLLA ${ }^{19}$ or PVDF $^{20}$ In the boundary region between spherulites a valley is observed as a consequence of the polymer crystallization process based on spherulite nucleation and growth. ${ }^{20}$ Further, AFM measurement performed in an area of $1 \times 1$ $\mu \mathrm{m}^{2}$, within a spherulite, lead to a rms roughness value of $8.4 \pm 2.7 \mathrm{~nm}$ [Fig. 1(d)].

Similar experiments were performed in PLLA electrospun fibers, were crystallization occurs in a confined environment because of fiber dimensions and were a different scale roughness is observed because of interfiber placement in the fiber membrane. Thus, AFM measurements were performed in single electrospun fibers subjected to similar annealing treatments as the ones performed in the films. Figure 2 shows the characteristic topography of PLLA electrospun fibers with different degrees of crystallinity. The electrospinning process gives origin to amorphous PLLA electrospun fibers. ${ }^{15-17}$ Amorphous electrospun fibers present an rms of $3.1 \pm 0.7 \mathrm{~nm}$ in an area of $1 \times 1 \mu \mathrm{m}^{2}$ and clear microstructural features are observed and identified as different heights [Fig. 2(a,b)]. After annealing at $140^{\circ} \mathrm{C}$ for $24 \mathrm{~h}$ electrospun samples with $50 \%$ of crystallinity show an rms value of $4.7 \pm 1.6 \mathrm{~nm}$ (for the same area).

The evolution of PLLA film and electrospun fiber roughness with the degree of crystallinity for different scanning areas is presented in Figure 3. It is observed that sample roughness does not show significant changes in the average surface roughness for PLLA films with degrees of crystallinity up to $30 \%$, independently of the scanning area. On the other hand, for film samples with higher degrees of crystallinity, the sample roughness suffers a strong increase from $2.3 \pm 2.7 \mathrm{~nm}$ up to $45.6 \pm 1.6 \mathrm{~nm}$ [Fig. 3(a)] for the lowest $\left(1 \times 1 \mu^{2}\right)$ and largest $\left(20 \times 20 \mu \mathrm{m}^{2}\right)$ scanning samples area, respectively. The evolution of the roughness with the degree of crystallinity for the single electrospun fibers shows that surface roughness just slightly increases with increasing crystallinity [Fig. 3(b)], which is due to the small sampling area at which this measurements must be performed (maximum of $1 \times 1 \mu^{2}$ ) in comparison to the films. The annealing treatment performed to the PLLA fibers reveals that the developed spherulitic microstructure in 

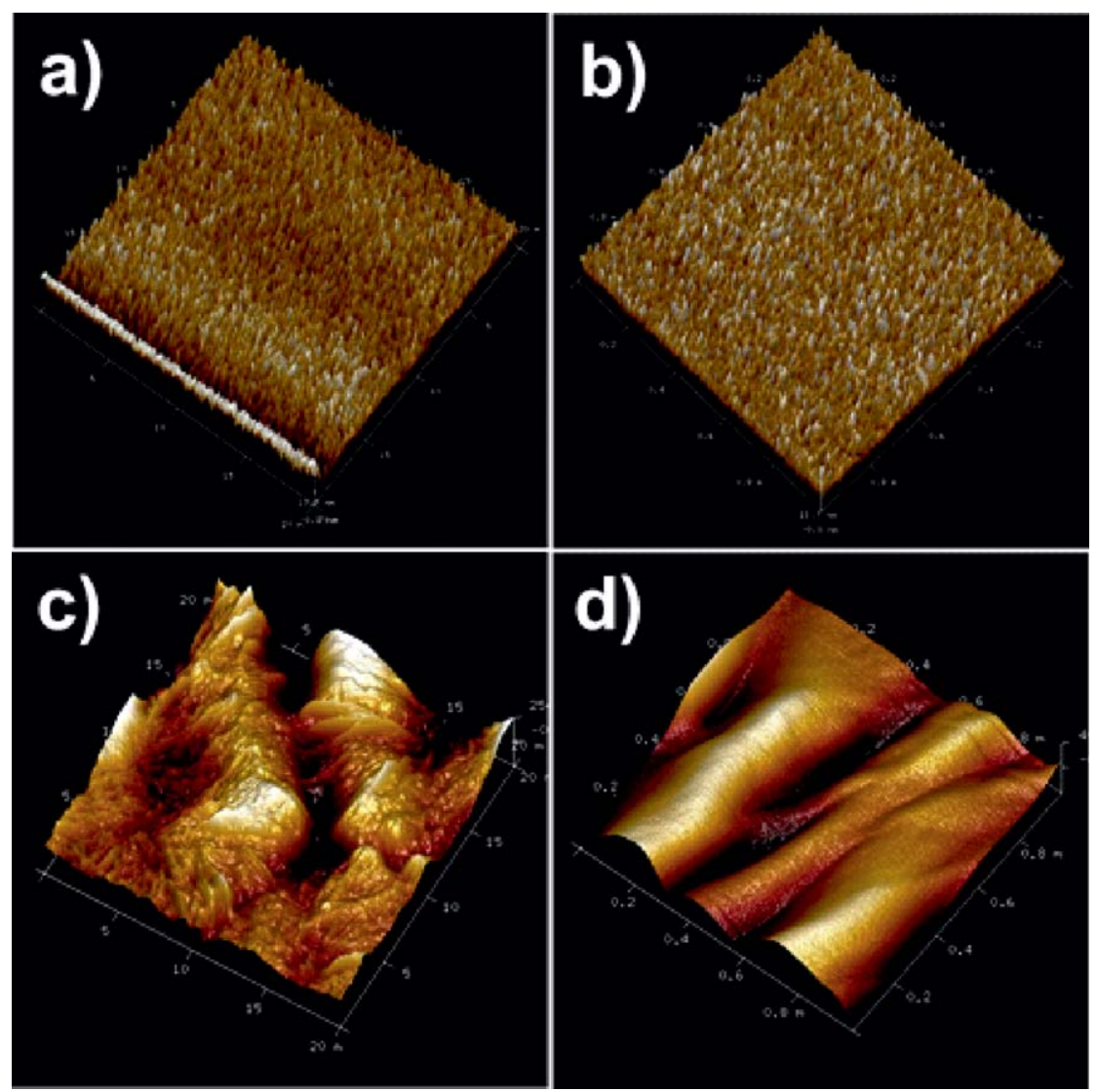

FIGURE 1. Representative AFM images showing the evolution of the PLLA morphology as a function of annealing time and therefore degree of crystallinity: (a, b) amorphous polymer sample measured at areas of $20 \times 20 \mu \mathrm{m}^{2}$ and $1 \times 1 \mu \mathrm{m}^{2}$, respectively; and (c, d) sample with $50 \%$ crystallinity measured at areas of $20 \times 20 \mu \mathrm{m}^{2}$ and $1 \times 1 \mu \mathrm{m}^{2}$, respectively. [Color figure can be viewed in the online issue, which is available at wileyonlinelibrary.com.]

polymer films during thermal annealing, with spherulites larger than $16 \mu \mathrm{m}$ of diameter after $24 \mathrm{~h}$ annealing [Fig. $1(\mathrm{c}, \mathrm{d})]$ cannot be developed in the fibers due to the confinement restrains related to the fibers small diameter ( $\sim 600 \mathrm{~nm}$, Fig. 2). On the other hand and despite this confinement effects, crystallization of polymer chains effectively occur, leading to similar degrees of crystallinity of films and fibers. This fact indicates that the crystallization process where the polymer chains fold into stems to form crystalline lamellae between $\sim 10$ up to $20 \mathrm{~nm},{ }^{21}$ leading to the characteristic spherulitic morphology of semicrystalline polymers, especially from when crystallization occurs from the melt, ${ }^{22}$ is only perturbed at the upper spherulitic level due to the confined space of the polymer fibers. It has been reported in related systems such as poly(ethylene oxide) ${ }^{21}$ that the process of nucleation and growth can be deeply affected by nanoscale confinement, as the isotropic growth of lamellar crystals is hampered and crystallization under confined conditions can produce specific lamellar crystallization. Often, the preferred lamellar crystal orientation is vertical to the layer. ${ }^{21,23}$ In the present work, such PLLA confinement provided by the fibrous morphology, probably results in the growth of crystalline lamellae in the radial direction towards fiber surface, promoting an increase in the overall fiber roughness with increasing degree of crys- tallinity (Figs. 2 and 3). Taken into account the sampling scale, the overall roughness of fibers and films of a sampling area of $1 \times 1 \mu \mathrm{m}^{2}$ is roughly at the same level. In this way, and for cell culture and related applications, in the PLLA fiber mats the main contribution for the sample overall roughness is not due to single fiber roughness but to the "peak and valleys" that exists between fibers due to fiber packing into the membranes.

\section{Contact angle measurements}

The surface energy, which is intimately related to the contact angle, is one of the key factors governing cell/biomaterial interaction. It has been reported nevertheless that there is no obvious relationship between cell adhesion and surface energy. ${ }^{24,25}$ On the other hand, studies have revealed that better adhesion and cell responses are obtained in biomaterial surfaces with moderate hydrophilicity. ${ }^{26,27}$ The results of the water contact angles measured on the different PLLA samples are shown in Table III. The contact angle of the PLLA films is lower than $90^{\circ}$, independently of the degree of crystallinity. Increasing crystallinity decreases the contact angle, being the film with the larger contact angle, $72.5 \pm 1.9$, the amorphous PLLA one.

Comparing the PLLA films and fibers, it is possible to observe that the PLLA fibers show a higher contact angle 

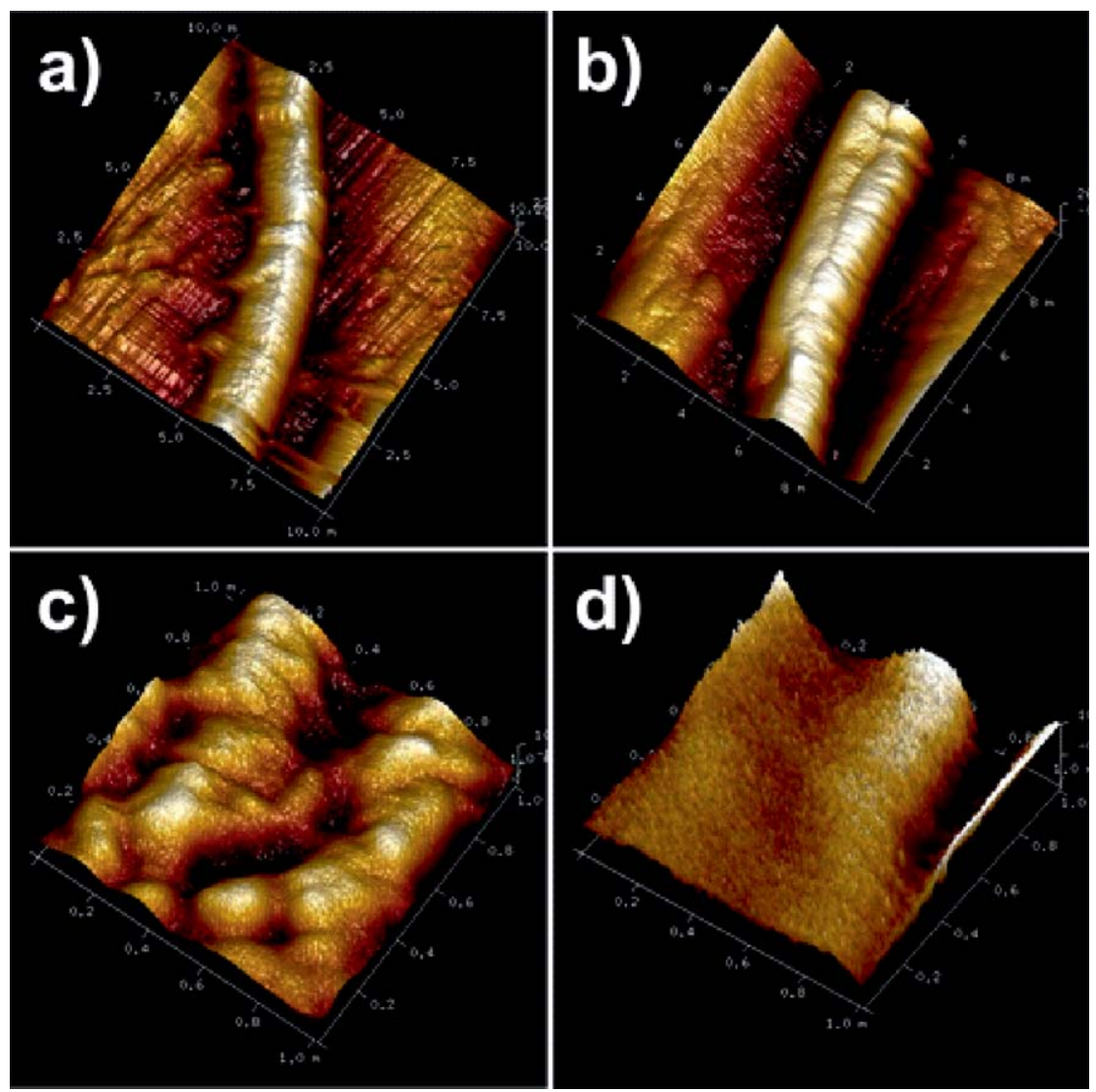

FIGURE 2. Representative AFM images showing the evolution of the surface morphology of PLLA electrospun fibers: (a, c) amorphous polymer sample at sampling areas of $10 \times 10 \mu \mathrm{m}^{2}$ and $1 \times 1 \mu \mathrm{m}^{2}$, respectively; and (b, d) sample with $50 \%$ crystallinity at sampling areas of $10 \times 10 \mu \mathrm{m}^{2}$ and $1 \times 1 \mathrm{~m}^{2}$, respectively. [Color figure can be viewed in the online issue, which is available at wileyonlinelibrary.com.]

than the PLLA films, exception made to the randomly oriented amorphous PLLA fibers.

On the other hand, the randomly aligned PLLA fibers show to be more hydrophilic than oriented PLLA fibers. Randomly oriented fibers show a strong increase in the contact angle from $\sim 66^{\circ}$ up to $\sim 118^{\circ}$ when crystallinity increases from amorphous material up to $50 \%$. When the fibers are oriented, the effect of increasing crystallinity is also to increase contact angle, although modestly: from $121^{\circ}$ (amorphous) to $138^{\circ}(50 \%)$, due to the already large contact angle value of the oriented amorphous fibers.

The contact angle difference between the PLLA films and fibers is explained by the large sub-micron range roughness produced by the electrospinning due to the fibrilar structure of the mats, ${ }^{28}$ explaining also the water contact angle dependence in electrospun mats on fiber orientation, porosity or fiber diameter. ${ }^{29,30}$
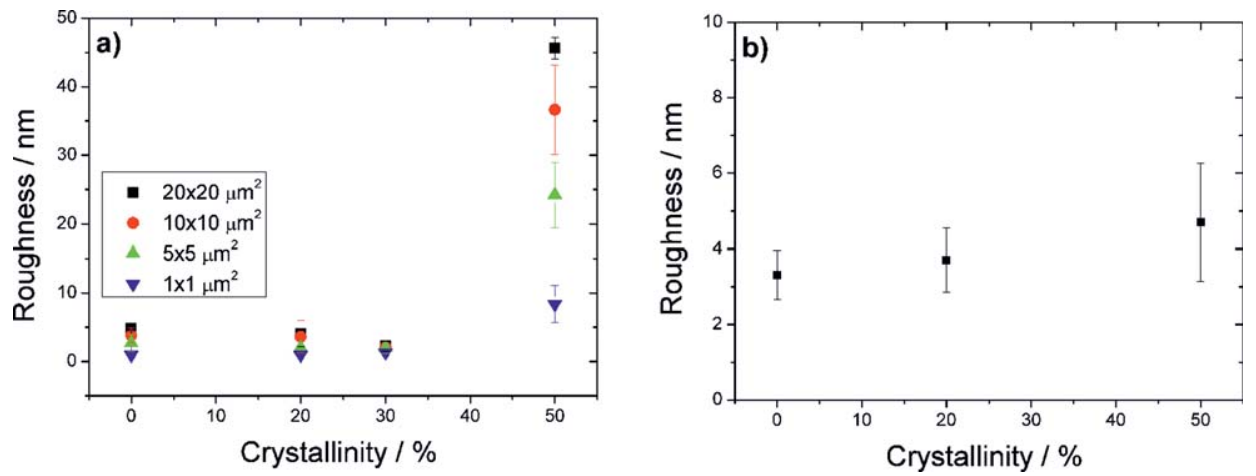

FIGURE 3. PLLA average roughness: (a) as a function of the degree of crystallinity for PLLA films, (b) as a function of the degree of crystallinity for a PLLA electrospun single fiber for a sampling area of $1 \times 1 \mu \mathrm{m}^{2}$. [Color figure can be viewed in the online issue, which is available at wileyonlinelibrary.com.] 
TABLE III. Contact Angle of the Different PLLA Samples

\begin{tabular}{lcc}
\hline PLLA Samples & Crystallinity & Contact Angle Values $\left(^{\circ}\right)$ \\
\hline Films & Amorphous & $72.5 \pm 1.9$ \\
& $20 \%$ & $56.0 \pm 7.7$ \\
Randomly & $50 \%$ & $61.9 \pm 6.2$ \\
oriented fibers & Amorphous & $65.9 \pm 2.4$ \\
& $20 \%$ & $86.8 \pm 2.5$ \\
Oriented fibers & $50 \%$ & $118.1 \pm 2.7$ \\
& Amorphous & $121.3 \pm 1.7$ \\
& $20 \%$ & $131.5 \pm 2.4$ \\
& $50 \%$ & $137.8 \pm 2.8$
\end{tabular}

Values are mean \pm SD.

When the PLLA films are submitted to thermal annealing, the contact angle value decreases associated to increasing roughness (Fig. 3, Table III).

A different behavior is observed in the fiber mats, in which the contact angle increases with increasing degree of crystallinity. In this case, the water drop is in contact with several fibers and the effect of the nanoscale roughness is overshadowed by the rearrangement of the fibers under thermal annealing that is by variations of the roughness at a micro-scale. Further, water contact angle increases stronger with thermal annealing in the randomly oriented fibers than in the oriented fibers, due to the larger reorganization of the fibers under thermal treatment. ${ }^{16}$

\section{Cell proliferation studies}

The influence of polymer topography on cell behavior is highly dependent on cell type and polymer material characteristics. ${ }^{31}$ So, in order to study the influence of PLLA crystallinity and surface roughness in cell attachment in an in vitro environment, two different cell lines were used: MC3T3-E1 preosteoblast and Mouse embryo fibroblast 3T3.

The proliferation of the attached cells on the different PLLA films throughout 6 days of culture is shown in Figures 4 and 5. The absorbance (Abs) was measured at $570 \mathrm{~nm}$ for all the

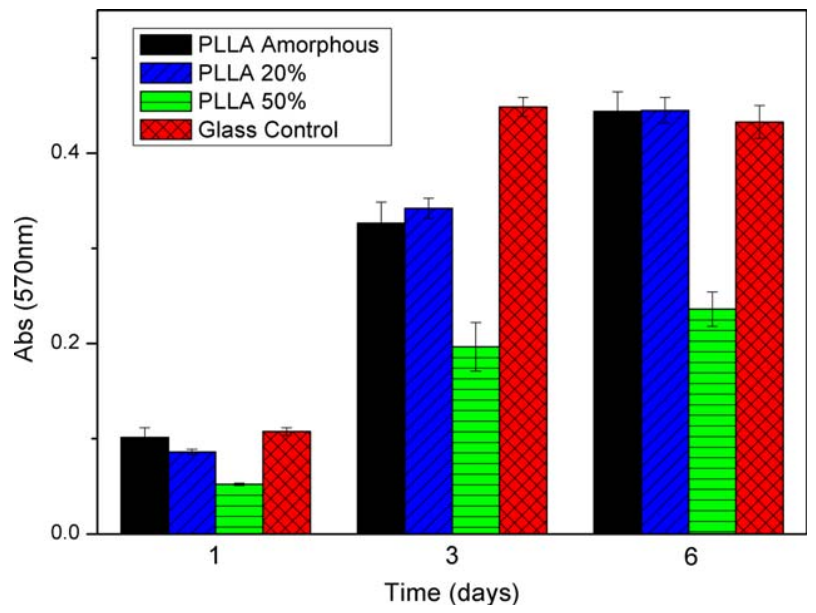

FIGURE 4. MTT results from proliferation assays of MC3T3-E1 preosteoblast seeded on different PLLA films and on the control surface after 1, 3, and 6 days. [Color figure can be viewed in the online issue, which is available at wileyonlinelibrary.com.]

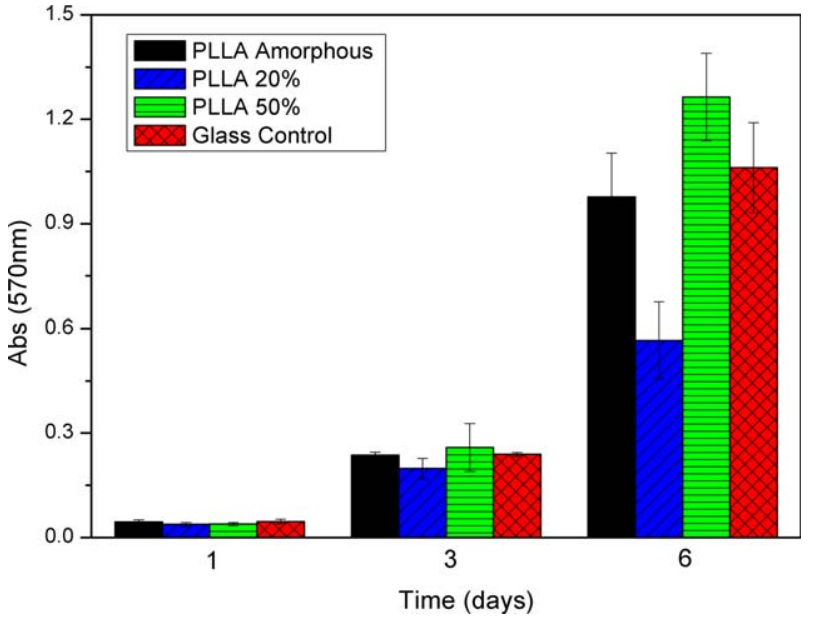

FIGURE 5. MTT results from proliferation assays of 3 T3 fibroblast seeded on different PLLA films and on the control surface after 1, 3, and 6 days. [Color figure can be viewed in the online issue, which is available at wileyonlinelibrary.com.]

samples at a given time. Figure 4 illustrates the MTT absorbance values obtained for MC3T3-E1 preosteoblasts cultured on PLLA films. After 1 day it is possible to observe that cell adhesion on PLLA with $50 \%$ of crystallinity is lower than on the other films with lower degree of crystallinity and surface roughness. This trend is accentuated for later stages of the culture; indeed, no significant increase over the third day is observed on PLLA with $50 \%$ of crystallinity.

Proliferation of 3T3 fibroblast on the different PLLA films is shown in Figure 5. After 1 and 3 days, no significant differences between the samples are observed. After 6 days, and contrary to the observations in MC3T3-E1 preosteoblast, the proliferation on PLLA films with $50 \%$ of crystallinity is significantly higher than for the other samples.

The cell proliferation was also studied, 3 days after cell seeding, on the different PLLA fibers and the results are illustrated in Figure 6. For MC3T3-E1 pre-osteoblast no significant differences between all substrates was detected. In

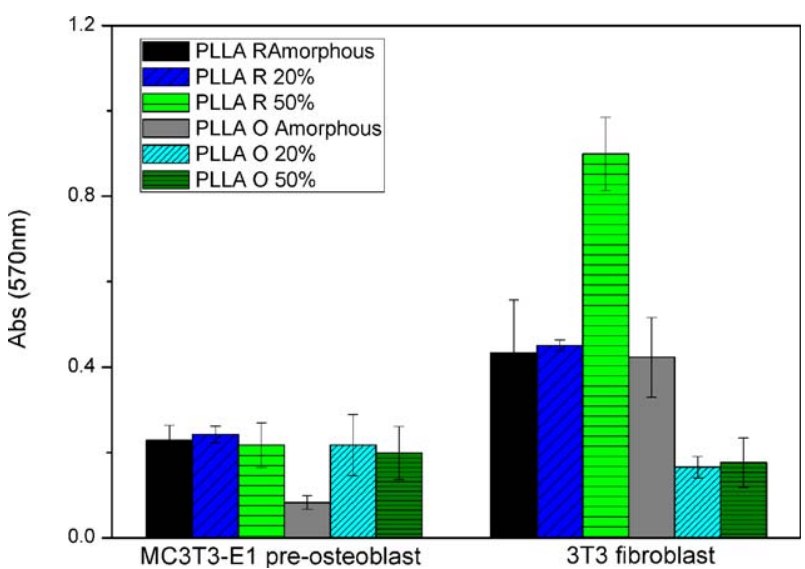

FIGURE 6. MTT results from proliferation assays of MC3T3-E1 preosteoblast and 3T3 fibroblast seeded on different PLLA electrospun mats after 3 days. [Color figure can be viewed in the online issue, which is available at wileyonlinelibrary.com.] 
the case of 3T3 fibroblast, the substrate that promotes higher proliferation is the PLLA R 50\% fibers. It was additionally found that cell viability is significantly lower in the case of oriented fibers with higher degree of crystallinity.

\section{DISCUSSION}

It is often observed in the literature studies with contradictory results with respect to the response of different cell types to surface topography. Previous studies show that cell types respond differently to different material surface roughness or topography. ${ }^{32}$ certain cells prefer smooth ${ }^{11}$ and another rough topography. ${ }^{33}$ Cells are highly sensitive to their surroundings responding to environmental features at different scale levels. As a consequence, it is essential to develop highly defined and specialized cell environments in order to achieve a proper tissue functional development. Cells respond to three different types of surface parameters: chemical, topographical, and mechanical. ${ }^{34}$ This work mainly focus on the topographic study as the chemical characteristics of the surface are the same in all PLLA films and membranes though variations at the mechanical level can be also expected due to the different mechanical characteristics of the amorphous and cystalline phases of the semicrystalline polymer.

The interface between cell and material plays an important role in cell attachment and behavior. Cell adhesion is mediated by membrane proteins that can be attached directly to the material or to the protein layer adsorbed on the substrate provided in the serum media. These proteins will be crucial for the formation of ECM and consequently for focal adhesions complexes. ${ }^{35}$ Spherulitic structures present on the film can promote the focal adhesions due to the protuberances. Focal adhesions complexes will dictate cell shape and cytoskeleton architecture, which has an important function on mechanotransduction. Perturbations to mechanotransduction at nanoscale level, compromises tensional homeostasis of the cells, once it will controls the cascade of intracellular signaling pathways leading to changes in gene expression and also form mechanisms to prevent cell apoptosis. ${ }^{36}$

In this study, it was verified that cell adhesion and proliferation of osteoblast and fibroblast cells is different in the substrates with different morphology. Comparing the different crystallinities of PLLA films, it is observed that the crystallinity affects differently the cell response. PLLA with 50\% of crystallinity (sample with higher roughness) shows the lowest osteoblast proliferation and the highest fibroblast proliferation. Such observation is contrary to the reports with osteoblast (hFOB1.19) and fibroblast (L929) cells that indicate that osteoblastic cells prefer rougher surfaces, whereas fibroblasts (the most common cell type found in connective tissue) favor smoother ones. ${ }^{32}$ On the other hand, our results are in agreement with previously reported results in which it was shown that the smoother the surface, more the osteoblast proliferate. ${ }^{37}$ The aforementioned variations in the literature can be attributed to the fact that the cell lines are different. It is interesting to notice that, as

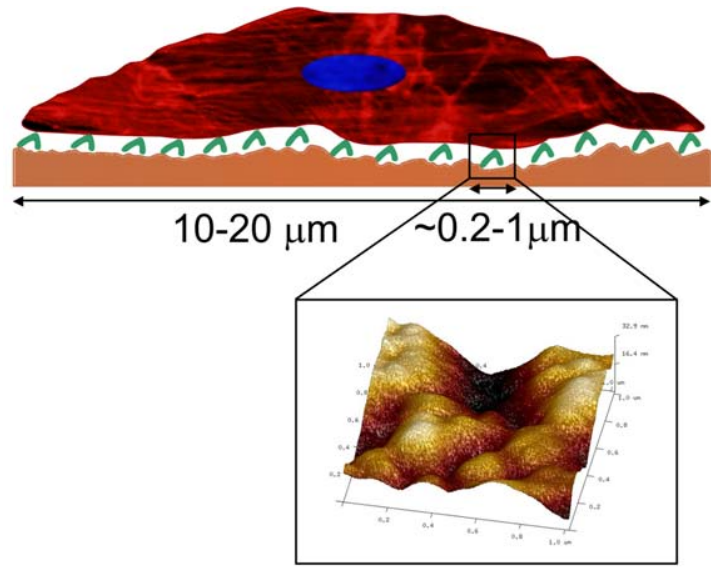

\section{A Cell adhesion receptor}

FIGURE 7. Relevant scales of cell adhesion. [Color figure can be viewed in the online issue, which is available at wileyonlinelibrary. com.]

the larger roughness differences are observed for the largest sampling area $(20 \times 20 \mu \mathrm{m})$, the "microscale roughness" seems to play a most relevant role in determining cell response, as compared to the "nanoscale roughness." Indeed, at the nanoscale level, all of the PLLA films analyzed bear a similar roughness, differences being observed only at the microscale level for the more crystalline sample, which seems to correlate with a differential cell response for both of the cell kinds used.

The biological response of human chondrocytes cultured in PLLA electrospun mats ${ }^{9}$ show that human chondrocytes proliferation is similar in both aligned and random amorphous mats and that the crystallization of the aligned mats, on the other hand, nearly suppresses proliferation. When comparing the different PLLA electrospun membranes (Fig. 6 ), it is observed that the orientation and crystallinity of the PLLA fibers seems not to affect the proliferation of the osteoblast cells. On the other hand, observing the biological response of fibroblast cells, it is verified that the PLLA randomly oriented with $50 \%$ of crystallinity promotes higher proliferation than the other PLLA electrospun mats, which is in agreement with the results for the PLLA films. However, for the same degree of crystallinity on the oriented PLLA fibers, the fibroblast proliferation was significantly lower. These PLLA electrospun membranes exhibit similar roughness, but the difference in fibroblast proliferation can be explained by the fact that the membranes surface present different topologies that result in different stimuli for the cell behavior.

Focal adhesions are the predominant mechanism by which cells mechanically connect to and apply traction forces on their ECM, playing therefore a critical role in cell behavior. ${ }^{38}$ The growth of cells can be modulated by physical factors such as ECM nanotopography. Such nanotopography can modulate cell behavior by changing focal adhesion $^{39}$ which in turn can change the cell adhesion and growth. So, the cell sense mechanical cues that guide their 
adhesion, growth and movements by probing their microenvironment at different scales (Fig. 7).

The overall results of this work indicate that the submicroenvironment variations (roughness for the samples with the different degrees of crystallinity) at a scale of $1 \times$ $1 \mu \mathrm{m}^{2}$ is similar for all samples and therefore, the critical role in determining the different cell responses is to be attributed to the roughness associated to larger areas $(20 \times$ $20 \mu^{2}$ ) in which larger differences are observed between the samples.

\section{CONCLUSIONS}

Poly(L-lactide) electrospun mats with random and aligned fiber orientation and films have been produced with degrees of crystallinity from 0 up to nearly $50 \%$. The surface roughness of the films is independent of the degree of crystallinity for degrees of crystallinity up to $30 \%$, being also independent of the sampling area for sampling areas form 1 $\times 1 \mu \mathrm{m}$ up to $20 \times 20 \mu \mathrm{m}$. On the other hand, for larger degrees of crystallinity up to $50 \%$, the surface roughness strongly increases and also shows a strong dependence on the sampling area. Finally, surface roughness variations with degree of crystallinity are smaller in electrospun mats due to the confinement effect of the fibers.

Samples with $50 \%$ of crystallinity (highest roughness) show the lowest osteoblast and the highest fibroblast proliferation indicating the relevant role of the submicroenvironment in determining cell responses of different cell types.

\section{REFERENCES}

1. Flemming RG, Murphy CJ, Abrams GA, Goodman SL, Nealey PF. Effects of synthetic micro- and nano-structured surfaces on cell behavior. Biomaterials 1999;20:573-588.

2. Anselme K, Bigerelle M, Noel B, Dufresne E, Judas D, lost A, Hardouin P. Qualitative and quantitative study of human osteoblast adhesion on materials with various surface roughnesses. J Biomed Mater Res 2000;49:155-166.

3. Lincks J, Boyan BD, Blanchard CR, Lohmann $\mathrm{CH}$, Liu Y, Cochran DL, Dean DD, Schwartz Z. Response of MG63 osteoblast-like cells to titanium and titanium alloy is dependent on surface roughness and composition. Biomaterials 1998;19:2219-2232.

4. Pamies P. Screening for topographies. Nat Mater 2011;10:808808.

5. Rebollar E, Frischauf I, Olbrich M, Peterbauer T, Hering S, Preiner J, Hinterdorfer P, Romanin C, Heitz J. Proliferation of aligned mammalian cells on laser-nanostructured polystyrene. Biomaterials 2008;29:1796-1806.

6. Kustra S, Bettinger CJ. Smart polymers and interfaces for dynamic cell-biomaterials interactions. MRS Bull 2012;37:836-846.

7. Lim JY, Donahue HJ. Cell sensing and response to micro- and nanostructured surfaces produced by chemical and topographic patterning. Tissue Eng 2007;13:1879-1891.

8. Ribeiro C, Moreira S, Correia V, Sencadas V, Rocha JG, Gama FM, Gomez Ribelles JL, Lanceros-Mendez S. Enhanced proliferation of pre-osteoblastic cells by dynamic piezoelectric stimulation. RSC Adv 2012;2:11504-11509.

9. Areias AC, Ribeiro C, Sencadas V, Garcia-Giralt N, Diez-Perez A, Gomez Ribelles JL, Lanceros-Mendez S. Influence of crystallinity and fiber orientation on hydrophobicity and biological response of poly(L-lactide) electrospun mats. Soft Matter 2012;8:5818-5825.

10. Mikulikova R, Moritz S, Gumpenberger T, Olbrich M, Romanin C, Bacakova L, Svorcik V, Heitz J. Cell microarrays on photochemically modified polytetrafluoroethylene. Biomaterials 2005;26: 5572-5580.
11. Washburn NR, Yamada KM, Simon Jr CG, Kennedy SB, Amis EJ. High-throughput investigation of osteoblast response to polymer crystallinity: influence of nanometer-scale roughness on proliferation. Biomaterials 2004;25:1215-1224.

12. Mikos AG, Sarakinos G, Lyman MD, Ingber DE, Vacanti JP, Langer R. Prevascularization of porous biodegradable polymers. Biotechnol Bioeng 1993;42:716-723.

13. Khang D, Choi J, Im Y-M, Kim Y-J, Jang J-H, Kang SS, Nam T-H, Song J, Park J-W. Role of subnano-, nano- and submicronsurface features on osteoblast differentiation of bone marrow mesenchymal stem cells. Biomaterials 2012;33:5997-6007.

14. Luckachan G, Pillai CKS. Biodegradable polymers-A review on recent trends and emerging perspectives. J Polym Environ 2011; 19:637-676.

15. Dias JC, Ribeiro C, Sencadas V, Botelho G, Ribelles JLG, Lanceros-Mendez S. Influence of fiber diameter and crystallinity on the stability of electrospun poly(L-lactic acid) membranes to hydrolytic degradation. Polym Test 2012;31:770-776.

16. Ribeiro C, Sencadas V, Costa CM, Ribelles JLG, Lanceros-Méndez S. Tailoring the morphology and crystallinity of poly(L-lactide acid) electrospun membranes. Sci Technol Adv Mater 2011;12:015001.

17. Sencadas V, Costa CM, Botelho G, Caparrós C, Ribeiro C, GómezRibelles JL, Lanceros-Mendez S. Thermal properties of electrospun poly(lactic acid) membranes. J Macromol Sci B 2011;51:411-424.

18. Costa Martinez E, Escobar Ivirico JL, Munoz Criado I, Gomez Ribelles JL, Monleon Pradas M, Salmeron Sanchez M. Effect of poly(L-lactide) surface topography on the morphology of in vitro cultured human articular chondrocytes. J Mater Sci: Mater Med 2007;18:1627-1632.

19. Xiao H, Liu F, Jiang T, Yeh J-T. Kinetics and crystal structure of isothermal crystallization of poly(lactic acid) plasticized with triphenyl phosphate. J Appl Polym Sci 2010;117:2980-2992.

20. Martins P, Lopes AC, Lanceros-Mendez S. Electroactive phases of poly(vinylidene fluoride): determination, processing and applications. Prog Polym Sci 2014;39:683-706.

21. Wang H, Keum JK, Hiltner A, Baer E, Freeman B, Rozanski A, Galeski A. Confined crystallization of polyethylene oxide in nanolayer assemblies. Science 2009;323:757-760.

22. Baer $E$, Hiltner A, Keith $H$. Hierarchical structure in polymeric materials. Science 1987;235:1015-1022.

23. Hamley IW, Fairclough JPA, Terrill NJ, Ryan AJ, Lipic PM, Bates FS, Towns-Andrews E. Crystallization in oriented semicrystalline diblock copolymers. Macromolecules 1996;29:8835-8843.

24. Ma Z, Gao C, Gong Y, Shen J. Chondrocyte behaviors on poly-Llactic acid (PLLA) membranes containing hydroxyl, amide or carboxyl groups. Biomaterials 2003;24:3725-3730.

25. Dahm M, Chang BJ, Prucker O, Pierkes M, Alt T, Mayer E, Rühe J, Oelert H. Surface attached ultrathin polymer monolayers for control of cell adhesion. Ann Thorac Surg 2001;71:S437-S440.

26. van Wachem PB, Beugeling T, Feijen J, Bantjes A, Detmers JP, van Aken WG. Interaction of cultured human endothelial cells with polymeric surfaces of different wettabilities. Biomaterials 1985;6:403-408.

27. Lee JH, Lee SJ, Khang G, Lee HB. The effect of fluid shear stress on endothelial cell adhesiveness to polymer surfaces with wettability gradient. J Colloid Interface Sci 2000;230:84-90.

28. Ma M, Hill RM, Rutledge GC. A Review of recent results on superhydrophobic materials based on micro- and nanofibers. J Adhes Sci Technol 2008;22:1799-1817.

29. Cho D, Zhou H, Cho Y, Audus D, Joo YL. Structural properties and superhydrophobicity of electrospun polypropylene fibers from solution and melt. Polymer 2010;51:6005-6012.

30. Zheng J, He A, Li J, Xu J, Han CC. Studies on the controlled morphology and wettability of polystyrene surfaces by electrospinning or electrospraying. Polymer 2006;47:7095-7102.

31. Ross AM, Jiang ZX, Bastmeyer M, Lahann J. Physical aspects of cell culture substrates: Topography, roughness, and elasticity. Small 2012;8:336-355.

32. Huag H-S, Chou S-H, Don T-M, Lai W-C, Cheng L-P. Formation of microporous poly(hydroxybutyric acid) membranes for culture of osteoblast and fibroblast. Polym Adv Technol 2009;20:1082-1090.

33. Rich A, Harris AK. Anomalous preferences of cultured macrophages for hydrophobic and roughened substrata. J Cell Sci $1981 ; 50: 1-7$ 
34. Gonzalez-Garcia C, Sousa SR, Moratal D, Rico P, SalmeronSanchez M. Effect of nanoscale topography on fibronectin adsorption, focal adhesion size and matrix organisation. Colloids Surf B 2010;77:181-190.

35. Zhou F, Yuan L, Huang $\mathrm{H}$, Chen H. Phenomenon of "contact guidance" on the surface with nano-micro-groove-like pattern and cell physiological effects. Chin Sci Bull 2009;54:32003205.

36. Stevens MM, George JH. Exploring and engineering the cell surface interface. Science 2005;310:1135-1138.
37. Linez-Bataillon $\mathrm{P}$, Monchau F, Bigerelle M, Hildebrand HF. In vitro MC3T3 osteoblast adhesion with respect to surface roughness of Ti6A14V substrates. Biomol Eng 2002;19:133-141.

38. Stricker J, Aratyn-Schaus Y, Oakes Patrick W, Gardel Margaret L. Spatiotemporal constraints on the force-dependent growth of focal adhesions. Biophys J 2011;100:2883-2893.

39. Yim EKF, Darling EM, Kulangara K, Guilak F, Leong KW. Nanotopography-induced changes in focal adhesions, cytoskeletal organization, and mechanical properties of human mesenchymal stem cells. Biomaterials 2010;31:1299-1306. 